\title{
Wnt Signaling Pathway Inhibitor SM08502
}

National Cancer Institute

\section{Source}

National Cancer Institute. Wnt Signaling Pathway Inhibitor SM08502. NCI Thesaurus.

Code C142777.

An orally bioavailable, small molecule inhibitor of the Wnt signaling pathway, with potential antineoplastic activity. Upon oral administration, SM08502 inhibits the expression of genes involved in the Wnt signaling pathway through an as of yet not fully elucidated mechanism. This decreased expression of Wnt pathway-related genes prevents Wnt signaling and may inhibit proliferation of cancer cells in which the Wnt signaling pathway is overactivated. The Wnt signaling pathway is dysregulated in many cancer cell types and plays a crucial role in tumor cell proliferation. 